\title{
Outcomes of incomplete thrombectomy in Wilms tumour with Intravascular extension - A Commentary
}

\author{
Tristan Boam ${ }^{1}$, Bethan Rogoyski ${ }^{2}$, Melissa Gabriel $^{3}$, and Paul Losty ${ }^{4}$ \\ ${ }^{1}$ Leicester Royal Infirmary \\ ${ }^{2}$ De Montfort University \\ ${ }^{3}$ Norfolk and Norwich University Hospitals NHS Foundation Trust \\ ${ }^{4}$ Alder Hey Children's NHS Foundation Trust
}

December 8, 2021

Tristan Boam ${ }^{1}$, Bethan G Rogoyski ${ }^{2}$, Melissa Gabriel ${ }^{3}$, Paul D Losty ${ }^{4}$

1. Department of Paediatric Surgery, Leicester Royal Infirmary, Leicester, UK

2. Leicester School of Allied Health Sciences, De Montfort University, Leicester, UK

3. Department of Urology, Norfolk and Norwich Hospital, Norwich, UK

4. Alder Hey Children's Hospital NHS Foundation Trust, School of Health and Life Science, University of Liverpool, UK

\section{Corresponding author}

\section{Mr Tristan Boam}

Department of Paediatric Surgery, Leicester Royal Infirmary, Infirmary Square, Leicester, LE1 5WW, UK

tristanboam@doctors.org.uk

$+447708825281$

Word count: 401

Number of tables/figures/materials: 0

Running title: Outcomes of incomplete thrombectomy in Wilms tumour

Keywords: Wilms; intravascular; thrombus; thrombectomy; cavectomy; cavotomy

Dear Editor,

A recent meta-analysis study exploring Inferior Vena Cava (IVC) thrombus viability following chemotherapy in Wilms tumour (WT) found thrombus non-viability in some $50 \%$ of cases.[1] The risks of IVC thrombectomy should therefore be weighed against the potential outcomes of incomplete resection.

Surgeons attempt thrombectomy with reportedly good outcomes with relatively few studies alleging thrombus left in situ.[2-5] However, where full extirpative resection is considered unfavourable, disease is upstaged with adjuvant caval irradiation mandated by current UK WT and COG guidelines. It is currently unclear whether this strategy achieves sufficient disease control to make caval surgery unnecessary. Highlighting this dilemma, non-viable thrombus was found in 5 of 7 of Ritchey's 1993 NWTS patients receiving pre-operative radiotherapy compared to malignant thrombus after 10 weeks neoadjuvant chemotherapy and radiotherapy in Renaud's single case. [6, 7] 
Extirpative surgery for IVC thrombus carries potentially lethal risks. In the UK WT3 study, 8 cases of significant bleeding with three associated case fatalities were recorded.[8] Fatal haemorrhage following attempts to resect an adherent hepatic vein thrombus has also been described. $[9,10]$ These reports are likely an underscored representation of the true incidence of major haemorrhage.

A concern of incomplete thrombectomy is increased danger of relapse or recurrence in the vascular or thoracic compartments, however extent of risk remains contentious.

In a meta-analysis we presented 8 reports on the recorded outcomes of incomplete resection. Of two studies $(\mathrm{n}=5[11], \mathrm{n}=6[12])$ authors reported individual incidences of pulmonary[11] and peritoneal relapse,[12] whilst 3 publications showed lung metastases $(n=4 / 13)[13]$; relapse $(n=2 / 18)[2]$; and mortalities from progressive disease $(n=6 / 10)[5]$ following incomplete resection. A single study reported 2 sudden deaths which were not clearly linked to known residual thrombus. [4] Loh et al postulated that complete IVC occlusion is a better predictor of adverse physiological outcome than completeness of thrombus resection, [14] Imle reported a good outcome for their single case of incomplete resection of extensive thrombus.[3] Since our original publication, IMPORT has reported outcomes of patients with intravascular extension. Tumour-related deaths and most relapses were associated with viable thrombus with macroscopic incomplete resection. Event-free survival was worse, but overall survival was unaffected when associated with incomplete thrombectomy.[1, 15]

It is crucial that we evaluate risks and benefits to patients and families when considering aggressive oncological surgery. Future studies are obligatory to establish if incomplete resection and adjuvant chemoradiotherapy are preferable to thrombectomy in complex cases. A surgeon led co-operative trial may provide a definitive answer.

\section{Conflict of interest}

The authors declare no conflict of interests

\section{Funding}

No specific funding declared

\section{References}

1. Boam TD, Gabriel M, Shukla R, Losty PD. Impact of neoadjuvant chemotherapy on thrombus viability in patients with Wilms tumour and caval extension: systematic review with meta-analysis. BJS Open , 2021 5 .

2. Shamberger RC, Ritchey ML, Haase GM, Bergemann TL, Loechelt-Yoshioka T, Breslow NE, Green DM. Intravascular extension of Wilms tumor. Ann Surg, 2001 234: 116-121.

3. Imle R, Tosev G, Behnisch W, Schenk JP, Rauch H, Mueller A, Gorenflo M, Loukanov T, Kulozik A, Nyarangi-Dix J. Intracardiac Extension of Wilms Tumor: A Case of a 2.5-Year-Old Girl Presenting with Upper Venous Congestion Caused by Tumor Growth into the Right Cardiac Ventricle. Case Rep Oncol , 2019 12: 33-38.

4. Szymik-Kantorowicz S, Urbanowicz W, Malec E, Kordon Z. Right atrial extension of Wilms' tumor. Med Sci Monit, 20039.

5. Akyuz C, Emir S, Buyukpamukcu N, Atahan L, Caglar M, Kutluk T, Buyukpamukcu M. Cavoatrial tumor extension in children with wilms tumor: a retrospective review of 17 children in a single center. J Pediatr Hematol Oncol , 2005 27: 267-269.

6. Ritchey ML, Kelalis PP, Haase GM, Shochat SJ, Green DM, D'Angio G. Preoperative therapy for intracaval and atrial extension of Wilms tumor. Cancer, 1993 71: 4104-4110.

7. Renaud EJ, Liu D, Pipe SW, Rubin MA, Teitelbaum DH. Inferior vena cavectomy for nonexcisable Wilms' tumor thrombus. J Pediatr Surg, 2001 36: 526-9. 
8. Lall A, Pritchard-Jones K, Walker J, Hutton C, Stevens S, Azmy A, Carachi R. Wilms' tumor with intracaval thrombus in the UK Children's Cancer Study Group UKW3 trial. J Pediatr Surg , 2006 41: $382-387$.

9. Abdullah Y, Karpelowsky J, Davidson A, Thomas J, Brooks A, Hewitson J, Numanoglu A, Cox S, Millar AJ. Management of nine cases of Wilms' tumour with intracardiac extension - a single centre experience. J Pediatr Surg , 2013 48: 394-399.

10. Cox SG, Davidson · A, Thomas · J, Brooks · A, Hewitson · J, Numanoglu · A, Millar · A J W. Surgical management and outcomes of 12 cases of Wilms tumour with intracardiac extension from a single centre. Pediatr Surg Int , 2018 34: 227-235.

11. Szavay P, Luithle T, Semler O, Graf N, Fuchs J. Surgery of cavoatrial tumor thrombus in nephroblastoma: a report of the SIOP/GPOH study. Pediatr Blood Cancer , 2004 43: 40-45.

12. Xu S, Sun N, Zhang WP, Song HC, Huang CR. Management of Wilms tumor with intravenous thrombus in children: a single center experience. World J Pediatr , 2019 15: 476-482.

13. Murthi G V, Kocyildirim E, Sellathury S, Cuckow PM, Wilcox DT, Michalski A, Sebire NJ, Elliott MJ, Duffy PG. Wilms' tumour with persistent intravascular extension: a review of the surgical aspects of management. J Pediatr Urol , 2006 2: 439-445.

14. Loh A, Bishop M, Krasin M, Davidoff AM, Jr MRL. Long-term physiologic and oncologic outcomes of inferior vena cava thrombosis in pediatric malignant abdominal tumors. J Pediatr Surg , 2015 50: 550-555.

15. Dzhuma K, Powis M, Vujanic G, Watson T, Olsen O, Shelmerdine S, Oostveen M, Brok J, Irtan S, Williams R, Tugnait S, Smeulders N, Mushtaq I, Chowdhury T, Al-Saadi R, Pritchard-Jones K. Surgical management, staging, and outcomes of Wilms tumours with intravascular extension: Results of the IMPORT study. J Pediatr Surg, 20210. 